\title{
Report of the 6th Japan-Germany Seminar*
}

\section{By Kazumi MORI,** Chairman of the Executive Committee}

\section{Foreword}

On May 22 and 23, 1984, the 6th Japan-Germany Seminar was held in Sasakawa Hall situated at Mita in Tokyo. It was just two years since last seminar had opened in Düsseldorf, ${ }^{1)}$ and this was the $3 \mathrm{rd}$ convocation of this seminar in Tokyo.

After exchange of opinions with Verein Deutscher Eisenhüttenleute (VDEh), two themes of discussion were decided:

1) Injection Metallurgy, and

2) Phenomena in Solidification of Steel.

The decision of the themes had the following background. First, the themes were the most important technical problem facing us at present in steelmaking. Secondly, when considering the steelmaking level which Japan and Germany have attained so far, our focus of the seminar reports was placed on basic phenomena leading to innovative technical development, rather than on techniques already materialized, with a view to grasping incentive knowledge and ideas surely resulting in future development.

The German delegation consisted of 19 members, including 8 wives accompanying them, and headed by Dr. Alfred Randak (Krupp Stahl AG, Bochum) who had been the chief on the German side since the 3rd Seminar. The party left Japan on June 1 after seminars and visit to companies and universities.

\section{Members List of German Delegation}

\section{Leader}

Dr. mont. A. RANDAK

(Krupp Stahl AG)

\section{Members}

Dipl.-Phys. M. Dubke Prof. M. G. FrohberG Dr.-Ing. R. Heinke Depl.-Phys. R. Hentriah Prof. Dr.-Ing. D. Janke

Dipl.-Ing. R. JAUGH Prof. Dr.-Ing. R. Jeschar Dr. rer. nat. R. KEGK

(Technische Universität Glausthal) (Technische Universität Berlin) (Krupp Stahl AG)

(Krupp Südwestfalen AG)

(Max-Planck-Institut für Eisenforschung $\mathrm{GmbH}$ (ARBED Saarstahl GmbH)

(Technische Universität Clausthal) (VDEh-Institut für angewandte Forschung $\mathrm{GmbH}$ )

Prof. Dr.-Ing. K. W. Lange (Technische Hochschule Aachen)

Dr.-Ing. H. Littersaheidt (Thyssen Stahl AG)

Prof. Dr. phil. F. Oeters (Technische Universität Berlin)

Dr.-Ing. W. Plusahkeld (Hoesch Hüttenwerke AG)

Dr.-Ing. J. Pötschke (Krupp Forschungsinstitut)

Dpl.-Ing. R. Steffen (Verein Deutscher Eisenhüttenleute)

Prof. Dr.-Ing. E. Steinmetz (Haus der Technik)
Dr.-Ing. R. Thielmann (Thyssen Edelstahlwerke AG) Prof Dr.-Ing. H. Wilhelmi (Technische Hochschule Aachen) Dr.-Ing. K. Wünnenberg (Mannesmann Forschungsinstitut $\mathrm{GmbH})$

\section{Outline of Seminar}

The 1st theme, Injection of Metallurgy, was reported and discussed in the 1st and 2nd sessions on May 22 and 2nd theme, Phenomena in Solidification of Steel, in the 3rd and 4th sessions on May 23. In the opening address, Prof. Mori told, on behalf of the Chairman of the Executive Committee, the significance of the themes selected for the seminar, and Dr. Randak stated, on behalf of the German delegation, excellent results to be obtained from reports and discussions of the seminar made by Japanese and German scientists and engineers working on a high technical level in the same fields.

(Reported by Kazumi Mori)

In the 1st session, the following five papers were subject to report and discussion.

Chairmen: E. Steinmetz (Haus der Technik) and K. S. Goto (Tokyo Institute of Technology)

1. Flow Velocities and Mixing at Blowing of Gas into Liquids

by F. Oeters (Technische Universität Berlin)

2. Physical Interactions between Injected Gas and Liquid in the Initial Jet Formation Zone by K. Mori (Nagoya University)

3. Dimensional Analysis of the Heterogeneous Buoyancy Plume by W. Pluschkell (Hoesch Hüttenwerke AG)

4. On the Behaviour of Penetration and Dispersion of Particle in Powder Injection Process by K. Ogawa (Kobe Steel, Ltd.)

5. Water Model Studies on Gas Stirring in Bottom Blown Steel Ladles

by H. Wilhelmi (Technische Hochschule Aachen)

This session started with a brief summary of a steelmaking progress story told by Prof. Steinmetz. Paper 1 treats results of model tests concerning liquid flow velocities and mixing time when blowing gas into liquids. Paper 2 is a creative research which can clarify under what condition bubbling-jetting transition occurs, by observing gas jet behavior by highspeed photography when injecting gas into liquids.

Paper 3 treats an analysis of the diameter, axial speed, volumetric flow speed, etc., of a plume zone

* Received September 4, 1984. (C) 1984 ISIJ

** Department of Iron and Steel Engineering, Faculty of Engineering, Nagoya University, Furo-cho, Chikusa-ku, Nagoya 464. 
formed by gas blowing, based on water model studies. Paper 4 is a study covering the powder distribution when injecting powder into water and $300 \mathrm{~kg}$ molten steel.

Paper 5 is an analysis, based on water model tests, of various factors influencing mixing time in liquid stirred by gas blowing. At the end of this session, the chairman gave his summary view on the reports and discussions made during the session and touched on an outlook for future studies.

(Reported by Kazuhiro S. Gото)

In the 2nd session, were reported six papers on a variety of subjects ranging from model test at room temperature to refining reaction at high temperature. On these reports, the Japanese and German participants had animated discussions.

Chairmen: W. Pluschkell (Hoesch Hüttenwerke AG) and K. Mori (Nagoya University)

6. Vortex Formation during Drainage of Metallurgical Vessels

by M. Dubke (Technische Universität Glausthal)

7. Physical Behavior of Bubbles in Molten Iron and the Nitrogen Transfer

by M. Kawakami (Toyohashi University of Technology)

8. Effect of Melting Scrap on the Mixing-time of Bottom Gas Stirred Melts

by K. W. Lange (Technische Hochschule Aachen)

9. Comparison of Refining Characteristics of Hot Metal between Soda Ash and CaO-based Fluxes in Powder Injection Process

by Y. Nakajima (Nisshin Steel Co., Ltd.)

10. Development of $\mathrm{CaCO}_{3}$ Base Flux to Desulfurize Hot Metal down to $10 \mathrm{ppm}$

by Y. Hara (Kawasaki Steel Corp.)

11. Possibilities of Low-phosphorus Steel Production by D. Janke (Max-Planck-Institute für Eisenforschung $\mathrm{GmbH}$ )

The German paper 6 treats the formation of vortex during tapping of molten steel from a converter or ladle, mechanism of slag carry over ensuing from the vortex formation and measures for vortex suppression, which were clarified by model tests with water and mercury. In addition, the technique for vortex suppression was tested in plant operation on a $\mathrm{BOF}$ unit. It was extremely impressive to see that various questions concerning practical applications, raised by Japanese participants were answered adequately with great enthusiasm by the German reporter belonging to university. Paper 8 treats the effect of melting scraps on the mixing-time of bottom gas stirred melts, which was studied with water model tests. Questions on this study were given on the relation between bath stirring and vessel shape. Paper 11 deals with the studies on the dephosphorization equilibrium between highly basic slag containing no $\mathrm{SiO}_{2}$ and molten iron using the levitation melting technique. Dephosphorization studies were further made by top slag treatment and powder injection.
There were questions about content of oxygen in molten iron, action of $\mathrm{CaF}_{2}$, etc.

The Japanese paper 7 concerns a research aiming at determination of bubble distribution, bubble rising speed and total surface area of bubbles by using an electroresistivity probe technique in gas injection into molten iron, as well as mass transfer coefficient in absorption and desorption of nitrogen under gas injection condition. The German participants put detailed questions on behavior of bubbles. Paper 9 is a study in which comparison is made between soda ash and $\mathrm{CaO}-X\left(X=\mathrm{CaF}_{2}, \mathrm{NaF}, \mathrm{CaCl}_{2}\right)$ concerning their behavior of dephosphorization and desulfurization, based on experiments of injecting powder into molten iron. Concerning this paper, there were wide-ranging questions, for example, effects of $\mathrm{Si}$ and $\mathrm{Mn}$ in molten iron, definition of total oxygen and phosphorus distribution ratio, relation between distribution ratio and basicity, etc. Paper 10 shows the possibility of desulfurization down to a low content by injecting flux containing mainly $\mathrm{CaCO}_{3}$ into molten iron in a torpedo car. In addition, the reaction mechanism was discussed. There were a variety of questions from the German side, i.e., effect of $2 \mathrm{CaO} \cdot \mathrm{SiO}_{2}$ formed on particle surface layers, formation of splash and metal loss during blowing, lance depth, scatter in data on desulfurization degree, etc. These questions indicated that the German participants had a deep interest in this field.

(Reported by Kazumi Morr)

In the 3rd session, two papers on heat transfer analysis, and three papers on mathematical analyses of phenomena in solidification of steel were presented.

Chairmen: F. Oeters (Technische Universität Berlin) and K. Kawakami (Nippon Kokan K.K.)

12. Heat Transfer during One- and Two Phase Water-spray Cooling of Hot Metals by R. Jeschar (Technische Universität Glausthal)

13. Application of Boundary Element Method to Solidification Process

by T. Umeda (The University of Tokyo)

14. Investigation of the Heat Transfer and the Temperature Distribution in Slabs during Continuous Casting by Means of Thermoelectrical Measurements by H. Litterscheidt (Thyssen Stahl AG)

15. Flow Phenomena during Solidification and Casting Defects in Steel Ingots

by I. Ohnaka (Osaka University)

16. Investigation of Internal Crack Formation in Continuous Casting Using a Hot Model

by K. Wünnenberg (Mannesmann Forschungsinstitut $\mathrm{GmbH}$ )

Paper 12 analyzes the heat transfer coefficient of spray and mist cooling by both steady-state and unsteady-state experiments. The heat transfer coefficient depends greatly on the density of water flux and the surface temperature (excluding the boiling zone), and is scarcely influenced by the momentum 
of water drops. The Leidenfrost point is a function of the water flux density and the material of a cooled object. Discussions were made about little influence of the momentum on the heat transfer coefficient, the constant heat transfer coefficient in the boiling zone, and the point that the heat transfer coefficient is in proportion to the water flux density. Paper 13 presents application of the boundary element method, which uses temperature recovery method, to the solidification process of castings with complicated forms. Discussions were made about the advantages of this method over the conventional methods, such as finite element method and finite difference method, expression of boundary conditions, and relationship between formation of shrinkage cavity and metallurgical factors. Paper 14 analyzes the temperature course of a continuously cast slab in the secondary cooling zone, which was measured by introducing thermocouples into the steel shell being cast, and pulling them down together with the shell during slab continuous casting. From the temperature measurement, the heat transfer coefficient at the directly sprayed zone and the area where the water drains off (radiation heat flux is important) was calculated. Paper 15 discusses the formation of porosity and macrosegregation in steel ingots by applying the direct finite difference method to the analysis of solidification phenomena including fluid flow. The paper also presents several subjects for a future study on solidification. The main points of discussion were the relationship between micro and macro models, absence of V-flow along the ingot center, and the formation mechanism of inverse $\mathrm{V}$ segregation. Paper 16 examines the effect of $\mathrm{C}, \mathrm{Mn}, \mathrm{S}$, and $\mathrm{Mn} / \mathrm{S}$ on the tendency to internal cracking of carbon steel by using hot bending simulation. The physical meaning of the crack parameters was discussed.

(Reported by Kiminari KawaKami)

In the 4th session, five papers on the continuous casting were presented as Part 2 of the 2 nd theme.

Chairmen: A. Randak (Krupp Stahl AG) and H. Matsunaga (Nippon Steel Corp.)

17. Mathematical Analysis of Macrosegregation among Dendrites

by H. Matsumiya (Nippon Steel Corp.)

18. Influencing the Solidification Structure in Strand Cast Blooms by Reversing Rotary Electromagnetic Stirring in the Secondary Cooling Zone

by R. Jauch (ARBED Saarstahl GmbH)

19. Solidification Phenomena of Continuously Cast Stainless Steel Billet

by K. Nakai (Sumitomo Metal Industries, Ltd.)

20. Solidification Phenomena during Horizontal Continuous Casting with Oscillating Mould

by R. Heinke (Krupp Stahl AG)

21. The Characteristics of Solidification in Horizontal Continuous Casting Process

by S. Takeda (Nippon Kokan K.K.)

Paper 17 presents a simple yet subtle mathematical model for microsegregation among dendrites of continuously cast slabs, and gives good agreement with the experimental results. Paper 18 aims at improvement of the solidification structure in strand cast blooms using various types of electro-magnetic stirring equipment, and concludes that rotary stirring is more advantageous than vertical stirring in obtaining large equiaxed core zone. A very animated discussion was made about the equiaxed crystal formation, and other subjects.

Papers 19, 20, and 21 concern the horizontal continuous casting. Paper 19 describes an investigation of the continuous casting process of austenite stainless steel, and shows the effectiveness of the multistage electro-magnetic stirring for improved solidification structure. Paper 20 describes development of the horizontal continuous casting with oscillating mould, and shows an interesting result that cold shut cracks and hot spots decrease markedly despite the use of a breaking assembly. Paper 21 reports the initial solidification phenomena and macrostructure revealed in the investigation of the horizontal continuous casting process, and shows the characteristics of solidification closely associated with the horizontal configuration of the caster.

(Reported by Hisashi Matsunaga)

The chairmen for the sessions stated the prospects and comments on the presentations.

At the beginning of the 1st session, Prof. Steinmetz stated that injection metallurgy was developed with mass production of argon in the history of development of steelmaking technology, and pointed out that researches in other fields can merit development of researches in his field. In summarizing remarks of the session, he described applicability of the model studies discussed in the session to actual environments, the meaning of the model experiments, and the problems to be solved. Prof. Goto pointed out that when the model experiments are reduced to production processes, the phenomena that might take place actually must be deliberately examined, and suggested the possibility of applying sensor technology to this problem. In the 2nd session, Dr. Pluschkell said that he agreed with Prof. Steinmetz in the meaning of similarity in the model experiments, but there was a difficult problem in selecting a suitable model scale when the experimental models were applied to actual processes, and therefore, the best way was to make measurements on actual equipment. Prof. Mori emphasized the importance of giving due consideration to the physical properties of gas-liquid, and remarked that the reaction of hot metal and steel, discussed in the latter half of this session, had been investigated in ditail in Japan, but he was very impressed by fresh questions made by the German side.

At the beginning of the 3rd session on solidification phenomena, Prof. Oeters remarked the scientific importance of the researches related to the secondary cooling which was to be presented from the German side and of the two studies on mathematical models presented from the Japanese side. As a summary 
statement, he noted that knowledge on temperature distribution in slabs during continuous casting and the relationship between the stress and cracking would lead to development of the secondary cooling method. In the 4th session, Dr. Randak explained the importance of the influence of the solidification process on the steel material's quality, and in his opinion, said that the horizontal continuous casting would become a standard process of casting at least the alloy steel in future. Dr. Matsunaga pointed out the importance of solving the problems in segregation in the continuous casting process, and stressed the necessity of encouraging basic researches of such essential problems.

The two themes discussed in the seminar are basic yet important problems in actual operation, and involve an interesting factor from the aspect of engineering science. But they have not been studied and discussed enough in academic circles in Japan. This seminar would give us an incentive to develop researches in this field.

\section{Visits to Universities and Companies}

After the closing of the seminar, the German delegation visited two universities and six companies: Faculty of Engineering and Research Institute of Mineral Dressing and Metallurgy, Tohoku University, and Faculty of Engineering, Nagoya University;
Kashima Steel Works, Sumitomo Metal Industries, Ltd., R \& D Labs.-I, Nippon Steel Corp., Tokuyama Industry, Co. Ltd., Mizushima Works, Kawasaki Steel Corp., Sanyo Special Steel Co., Ltd., Kobe Works, Kobe Steel, Ltd. They also made a sightseeing tour to Nikko. We are very grateful to the staff of the universities and companies for their considerable assistance during the visits.

\section{Conclusion}

The greatest number of attendants was recorded in this seminar for both German and Japanese sides. Substantial discussion were held in this seminar, and technical views and experience were exchanged in a friendly atmosphere. As Dr. Randak, the German delegation leader, says, this seminar has shown that especially Japan and Germany have very similar view about what should be done in the research and development looking for future technology, and this will assure the continuous friendly communications between the two countries through these seminars. In conclusion, we are very grateful to the members of the Executive Commitee and the staff of International Conference Section, ISIJ, for their strenuous efforts in preparations and management of this seminar.

\section{REFERENCE}

1) K. Mori: Tetsu-to-Hagané, 70 (1984), 446.

\section{Results of the 6th Japan-Germany Seminar 1984 in Tokyo*}

\section{By Alfred RANDAK,** Leader of the German Delegation}

The steel industries of Japan and Germany are in many ways similar in terms of competitive conditions and interests. Both Japan and Germany are industrialized countries with inadequate indigenous resources of raw materials and both have to compete on the world market with countries who enjoy the benefit of cheaper raw materials and lower wage costs.

The steel industries of both countries are therefore compelled to undertake great efforts in research and development with the aim of improving plant technology, developing new processes and changing to higher-value products. Their joint claim to be world leaders in iron- and steelmaking equipment and technology forms a strong bond between German and Japanese steelmakers, beyond their traditional links. We therefore welcome the fact that since 1974 Japanese and German metallurgists have met every two years to confer in a seminar of the fundamentals of iron- and steelmaking and to exchange and discuss their latest research findings in an atmosphere unburdened by the rivalry which undoubtedly exists between our two countries in selling steel on the world market.

\section{6th Japan-Germany Seminar}

The 6th Japan-Germany Seminar held in Tokyo on the fundamentals of iron- and steelmaking was superbly organized by the Chairman, Prof. K. Mori of Nagoya University, and by Mr. Tohru Kinoshita, Executive Director of the Iron and Steel Institute of Japan, and his colleagues.

The following is a brief evaluation of the technical content of the seminar and discussions.

On the topic of "Injection Metallurgy" there were new findings on the effects of different fluxes on

* Received October 5, 1984. (C) 1984 ISIJ

** Member of the Executive Board, Krupp Stahl AG, Bochum, F. R. Germany. 